\title{
Feasibility of a Grocery Store Tour for Parents and Their Adolescents: A Randomized Controlled Pilot Study
}

\author{
Cassandra J. Nikolaus, $\mathrm{MS}^{1}$; Matthew M. Graziose, $\mathrm{MS}^{2}$; \\ Sharon M. Nickols-Richardson, PhD, $\mathrm{RD}^{1,3}$
}

\begin{abstract}
Objective: To evaluate the feasibility of a grocery store tour for parents and their adolescents being led by adults or adolescent peers.

Design: Randomized controlled pilot study with surveys at baseline and post-program, and at 3- and 6-month follow-up.

Setting: Midwestern midsized grocery stores.

Participants: Sixty-one parents and their 71 11- to 14-year-old adolescents.

Intervention: Nutrition education during 1 90-minute grocery store tour.

Main Outcome Measures: Process observations and participants' tour perceptions provided fidelity outcomes. Questionnaires quantitatively assessed participants' knowledge, self-efficacy, and tour strategy use. Analysis: Chi-square and McNemar tests were used to analyze categorical data, and Kruskal-Wallis, Wilcoxon signed-rank, and Mann-Whitney U tests were employed for continuous variables (significance at $P<.05)$.

Results: Over $90 \%$ of tour tasks were rated as completed well for adult and peer leaders. Participants had positive tour perceptions but noted deficiencies in teen leaders' knowledge and leadership skills. Overall, parents and adolescents retained increased self-efficacy from pre-tour to post-tour intervals. Despite limited knowledge retention, parents reported they had increased $(6.5 \pm 4.19)$ healthful grocery shopping behaviors in the 6 months after the intervention.

Conclusions and Implications: Peers may feasibly lead grocery store tours but they may need additional resources and support to be highly effective.

Key Words: children, grocery shopping, grocery store tour, parents, peer education (J Nutr Educ Behav. 2017;49:827-837.)
\end{abstract}

Accepted July 19, 2017. Published online September 23, 2017.

\section{INTRODUCTION}

The average American spends roughly $\$ 563$ on food each month, with 59\% of these purchases from groceries ${ }^{1}$

and $42 \mathrm{~min} / \mathrm{wk}$ spent on grocery shopping. ${ }^{2}$ Grocery shopping behaviors are intertwined with many other decisions to help form individuals' dietary patterns. In the US, many adults

\footnotetext{
${ }^{1}$ Division of Nutritional Sciences, University of Illinois at Urbana-Champaign, Urbana, IL ${ }^{2}$ Department of Health and Behavior Studies, Teachers College Columbia University, New York, NY

${ }^{3}$ Department of Food Science and Human Nutrition, University of Illinois at UrbanaChampaign, Urbana, IL

Conflict of Interest Disclosures: The authors' conflict of interest disclosures can be found online with this article on www.jneb.org.

Address for correspondence: Sharon M. Nickols-Richardson, PhD, RD, Department of Food Science and Human Nutrition, University of Illinois at Urbana-Champaign, $905 \mathrm{~S}$ Goodwin Ave, Urbana, IL 61801; Phone: (217) 244-4498; Fax: (217) 265-0925; E-mail: nickrich@illinois.edu

(C2017 The Authors. Published by Elsevier, Inc. on behalf of the Society for Nutrition Education and Behavior. This is an open access article under the CC BY-NC-ND license (http://creativecommons.org/licenses/by-nc-nd/4.0/).

http://dx.doi.org/10.1016/j.jneb.2017.07.012
}

and adolescents fall short of meeting dietary recommendations, namely for intakes of fruits, vegetables, and whole grains. $^{3}$ Low diet quality among adolescents is of particular concern because evidence suggested that dietary patterns track into adulthood. ${ }^{4,5}$ Less healthful choices in grocery stores leading to lower-quality dietary patterns among parents and adolescents may result in part from confusion regarding nutrition facts labels, because many find them difficult to use. ${ }^{6}$

Nutrition education within grocery stores may increase comprehension and use of nutrition labels and improve consumers' food purchasing practices. Providing dietetics counseling in the grocery store setting was also shown to encourage healthful dietary and knowledge changes among patients with obesity, ${ }^{7}$ but this 1-on-1 education approach 
requires considerable time. Facilitatorled grocery store (or supermarket) tours take small groups, rather than individuals, through a grocery store to teach strategies and skills that enable healthful food purchasing choices. Based on the practicality that grocery stores provide contextual learning environments and consumable foods, supermarket tours have flourished as a nutrition education medium. However, there continues to be a gap in the literature rigorously testing the effectiveness of grocery store tours. A recent systematic review ${ }^{8}$ identified 8 studies evaluating grocery store tours, the majority of which used nonrandomized noncontrolled designs. As included in the systematic review, tours resulted in healthful purchasing behaviors and positive knowledge changes, $^{9-11}$ but there was significant heterogeneity across study populations and focal behaviors in previous tours.

There is a paucity of data investigating whether peer influences in the form of adolescent teen leaders (TLs) can have an impact on the efficacy of grocery store tours. Social Cognitive Theory (SCT) provides a model to predict behaviors based on the interaction of individuals and their environment as they learn. ${ }^{12,13}$ According to SCT, peers are instrumental in developing social outcome expectations and stimulating observational learning. ${ }^{13}$ Programs that included peer leaders were successful in tobacco-use prevention and sex education. ${ }^{14-16}$ Nelson and Nickols-Richardson ${ }^{17}$ conducted a systematic review of nutrition education programs that used peer leaders and concluded that mediators of dietary behavior change were positively influenced in some programs. In addition, studies demonstrated that peers influenced social norms, ${ }^{18}$ snack preferences, ${ }^{19}$ and quantity of food consumed among high school-and elementary schoolaged children. $^{20-22}$ This previous work provided a foundation for which the role of TLs in a grocery store tour is worth investigating.

\section{Study Objectives}

The purpose of this pilot study was to evaluate the feasibility of a grocery store tour led by adolescents (ie, teens or peer-led). Both parents and their adolescents were included in the intervention. It was hypothesized that (1) knowledge and self-efficacy would increase in participants after attending the tour; and (2) adolescent participants would have greater increases in knowledge and self-efficacy after a peer-led tour, compared with an adult-led tour.

\section{METHODS}

\section{Tour Development, Pretesting, and Modification}

Based on SCT and the peer-education model, a grocery store tour was developed that focused on encouraging healthy dietary patterns that could be taught by adolescent peers. Four experts in human nutrition designed the tour based on the 2010 Dietary Guidelines for Americans, a literature review of content in previous, similar programs, ${ }^{11,23-25}$ and related Extension materials. $^{26-29}$ The 2.5-hour tour was designed to meet 4 broad objectives, including food comparisons by ingredients and nutrition facts, food locations of the major food groups, food navigations among choices within food groups, and food cost savings among healthy foods. ${ }^{30}$ The walking tour used a structured group discussion format with hands-on activities and handouts.

Based on similar previously published literature, ${ }^{31,32}$ experts were recruited to evaluate the content validity of the tour lesson by assessing the overall relevance as well as the ability of activities to achieve the learning objectives. Eight content experts rated the tour content as somewhat relevant with some to high ability to achieve objectives. ${ }^{30,33}$ In addition, the tour was pretested with 9 parents and 15 adolescents (average age, 11.6 years) across 3 tours in 2 different grocery stores and 1 supermarket. On average, 124 minutes were required when the lesson was taught by an adult educator. Three post-tour focus groups indicated that all parents liked the tour, particularly the hands-on components, and some perceived that future grocery shopping trips with their adolescents might be easier and more enjoyable. Post-tour questionnaires evaluating the selfefficacy of participants to perform 15 behaviors encouraged in the tour indicated that parents felt confident they could use 14 of the behaviors taught.
Overall, the tour was a positive experience. Constructive comments from parents and adolescents were used to further improve lesson materials, including clarity of text and format and a reduction in the number of handouts as well as better instructions for activities. A mid-tour break with a healthy snack was added and the total length was reduced to 90 minutes. Participants requested notices regarding appropriate clothing to wear on the tour, owing to temperature fluctuations in various store sections.

\section{Recruitment, Screening, and Enrollment}

For the current pilot study, families were recruited between February and August, 2015, from the University of Illinois at Urbana-Champaign campus and Urbana and Champaign, IL, communities using word of mouth, e-mail messages, brief presentations to local groups, and fliers. Figure 1 displays enrollment, randomization, and attrition data. Eligibility for adults included being the parent or guardian of a child in the sixth or seventh grade with transportation and, for adolescents, being aged 11-14 years. Parents and adolescents attended a study information session, after which parents provided written informed consent, and adolescents written informed assent. The Institutional Review Board for the Protection of Human Subjects at the University of Illinois at UrbanaChampaign approved the study protocol. Families received a chance to win 1 of $3 \$ 25$ grocery store gift cards and also received a $\$ 10$ grocery store gift card at the 3-and 6-month follow-up intervals if they returned questionnaires.

\section{Study Design}

This was a 6-month randomized, controlled pilot study. Sixty-one families (61 parents and 71 adolescents) volunteered to participate. Families were randomly assigned to 1 of 3 groups: (1) an adult leader (AL) tour group ( $\mathrm{n}=21$ families), (2) a TL tour group ( $\mathrm{n}=20$ families), or (3) a control (CON) group ( $\mathrm{n}=20$ families). Participants in the AL and TL groups were assigned a date when 2-5 families could attend a tour. Parents confirmed attendance and were sent 


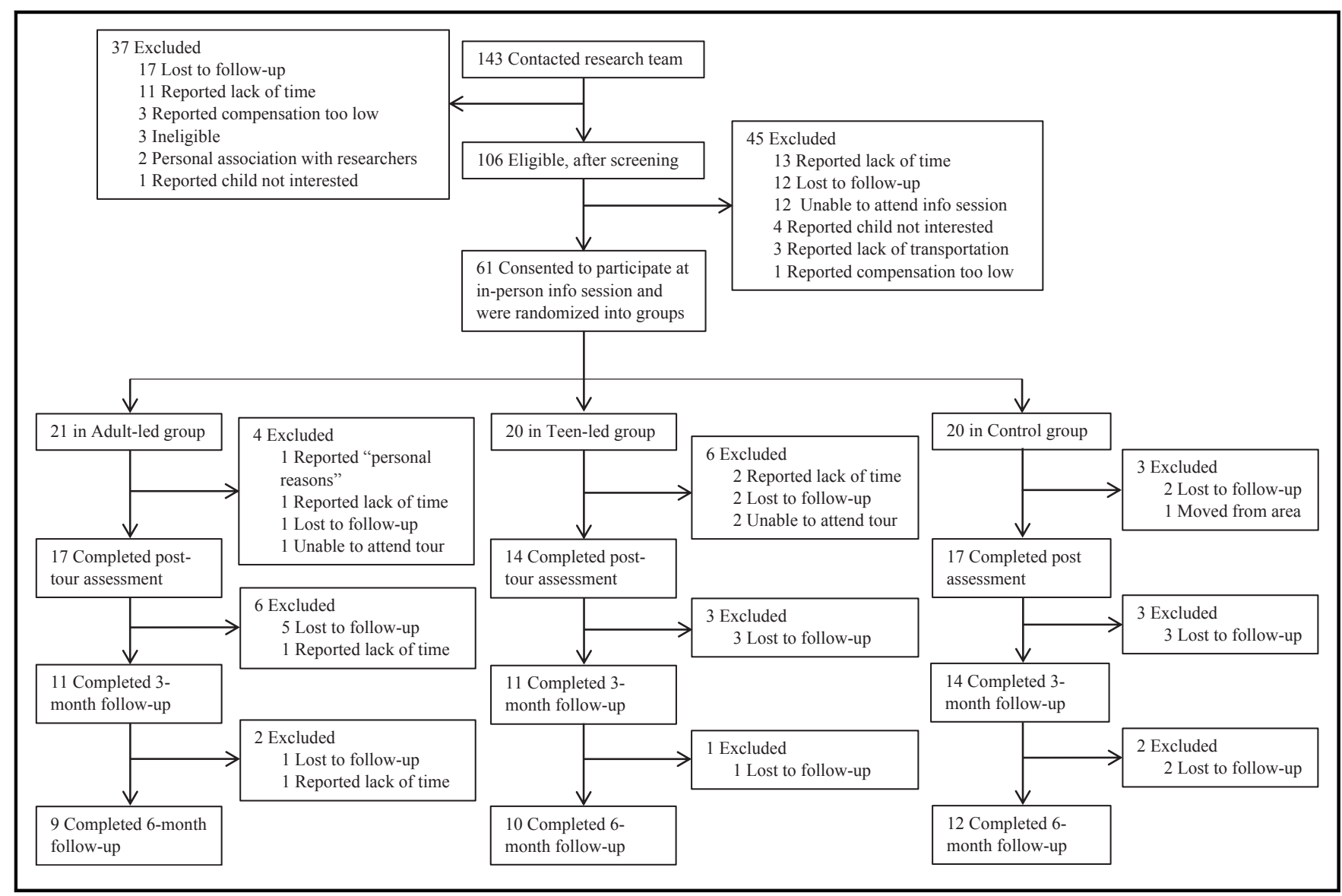

Figure 1. Flow diagram of recruitment and retention of families in a pilot study of a grocery store tour for parents and their adolescents.

reminders 2 days before their tour dates. The TL and AL tours were identical in curriculum; the only difference was the age of the leaders. Tours were a single 90-minute program with light refreshments provided during 1 10-minute break. Tours occurred in 1 of 2 midsize grocery stores in the community.

Adult leaders and TLs were volunteers from the community. Four ALs aged $>25$ years ( 3 women and 1 man) and 3 TLs aged 11-14 years (2 boys and 1 girl) were trained on the tour curriculum and materials using in-store as well as traditional lecture strategies. During 4 hours of training, leaders learned the tour objectives, segments, and content; received a mock tour; and practiced delivering the tour.

\section{Outcome Measurement Intervals}

Parents and adolescents completed assessments at 4 intervals: (1) before randomization (ie, pre), (2) after the tour (AL or TL) or 2 weeks after randomization (CON) (ie, post), (3) 3 months after the tour (AL or TL) or after post (CON) (ie, 3 months post), and (4) 6 months after the tour (AL or TL) or 6 months after post (CON) (ie, 6 months post). All participants completed paper questionnaires in person at baseline (pre). Families in the TL and AL groups also completed the post-tour assessment in person, whereas families in the CON completed questionnaires by mail or e-mail. At 3and 6-month post-intervals, all families completed questionnaires by mail or e-mail, based on preference.

\section{Outcome Measures}

The grocery store tour process was observed in accordance with recommendations, ${ }^{33}$ including measures of recruitment, context, reach, dose delivered, fidelity, and dose received.

Recruitment. Tactics used to recruit participants were recorded and responses were summarized based on frequency. Responses from participants indicating that they would not participate were also recorded and summarized when supplied, to identify patterns.

Context. Tours were administered in 2 midsize grocery stores located in 2 central Illinois cities. Census data from 2010 and $2014^{34}$ for surrounding towns were reviewed and summarized.

Reach. Parents completed a demographic questionnaire to report age, sex, race, ethnicity, marital status, number of children, education level, income, height, and weight (Table 1). Adolescents completed a similar questionnaire for age, sex, race, ethnicity, grade in school, and the name of the school. In addition, food security was assessed as a sociodemographic variable; parents completed the 18-item Household Food Security Survey Module, $^{35}$ and adolescents the Child Food Security Survey Module. ${ }^{36}$ 
Dose delivered. One process observer evaluated each tour using an investigatorestablished process observation checklist. The scheduled and actual start times, end time, and number of expected and actual attendees were recorded for each tour.

Fidelity. The process observer also evaluated the expected and actual completion of each discussion and activity within the tour (using the dichotomous variable of not completed well or completed well) (a checklist of items is presented in Table 2 under Assessment of Tasks). At least $80 \%$ of session tasks were required to be rated as completed well to confirm feasibility. General comments deemed relevant by the process observer were included in the checklist. At the post-assessment interval, parents and adolescents were asked to reflect actively on the tour experience by completing an investigator-designed perception of the tour questionnaire. This questionnaire contained open-ended items related to the overall tour, 5 items regarding activities, and 3 items about handouts.

Dose received. Knowledge and selfefficacy were assessed as proxies for dose received of the tour. Parents and adolescents completed investigatordesigned quizzes as assessments of grocery shopping-related knowledge, similar to those previously used after grocery store tours. ${ }^{11,37,38}$ Quizzes contained 10 items with 1 correct answer for each item (score range $=0-10$ ).

Parents and adolescents completed investigator-designed grocery shopping self-efficacy questionnaires. The self-efficacy questionnaire contained 15 statements of grocery shoppingrelated tasks and assessed confidence level in performing each on a scale of 1 (not at all confident) to 5 (extremely confident), comparable in format to those used in previous studies with adolescents ${ }^{39}$ and adults. ${ }^{40}$ The 15 items were averaged for an overall selfefficacy score (Cronbach $\alpha=.90$ for adults and .92 for adolescents at baseline). Knowledge and self-efficacy questionnaires were completed pre- and post-tour; difference between pre-post scores served as an indicator of dose received.
Program impact. Parents and adolescents repeated the self-efficacy and knowledge questionnaires at 3- and 6-month post-intervals to assess retention over time. Knowledge quizzes consistently covered tour content but had slight changes to item wording at each interval to discourage memorization of items. At 6 months post, parents completed a strategy utilization questionnaire to assess retrospectively the use of behaviors taught during the tour. The questionnaire included 18 statements of behaviors; response options were decreased, no change, or increased, coded as $-1,0$, and 1 , respectively, for a change score ranging from -18 to 18 .

\section{Data Analyses}

Using knowledge quiz score change with an effect size of $0.25,^{40}$ a power analysis using $\mathrm{G}^{\star}$ Power software ${ }^{41}$ indicated that 101 participants would be necessary for sufficient power. Researchers anticipated $85 \%$ retention, ${ }^{42,43}$ which resulted in the recruitment of 120 participants (60 parent-adolescent pairs).

Categorical data were analyzed with chi-square tests when comparing groups and McNemar test when comparing repeated measures over time. Because of nonnormal distributions and the small sample size, continuous variables were analyzed with nonparametric tests. ${ }^{44}$ KruskalWallis test compared groups and Wilcoxon signed-rank test compared change over time. If groups $(\mathrm{AL}, \mathrm{TL}$, and CON) had statistically significant differences by Kruskal-Wallis test, Mann-Whitney $U$ test was used to identify group differences. All analyses were conducted using SAS software (version 9.4; SAS Institute Inc, Cary, NC; 2011). Significance was set at $P<.05$.

Fidelity outcomes, which were derived from process observation notes and open-ended tour perception questionnaires, were evaluated for insights and future suggestions. Quantification as percentages by group was completed to identify differences between groups.

\section{RESULTS}

\section{Recruitment}

Of parents who contacted the research team, $65.0 \%$ (93 of 143) reported the recruitment method. Electronic listserv $(\mathrm{n}=36)$ was the most frequent, followed by fliers $(n=35)$, word of mouth $(\mathrm{n}=16)$, television report $(\mathrm{n}=4)$, and online advertising $(\mathrm{n}=2)$. Nonparticipation was most frequently due to nonresponse $(n=17)$ and self-reported lack of time $(\mathrm{n}=11)$.

\section{Context}

Census data for Urbana and Champaign, IL, respectively, indicated that the population was $49.9 \%$ and $49.1 \%$ female, $60.4 \%$ and $67.8 \%$ white, and $5.2 \%$ and $6.3 \%$ Hispanic/ Latino/Latina; $54.6 \%$ and $51.4 \%$ had a bachelor's degree or higher; and the annual household income was $\$ 20,304$ and $\$ 25,968$. ${ }^{34}$

\section{Reach}

Sixty-one families volunteered and 60 families completed baseline assessments. One family was unable to participate after consenting, owing to an emergency. Parents were aged $43 \pm 7$ years and primarily female, white, non-Hispanic, and married, with a bachelor's level of education or higher (Table 1). Adolescents were aged $12 \pm 1$ years and were primarily white and non-Hispanic. Adolescents attended 28 different area schools. Families closely resembled participants in a similar study ${ }^{45}$ but were not representative of sex, race, ethnicity, education, and income characteristics of the local areas.

At post-tour, 13 families had withdrawn from the study $(\mathrm{AL}=4,19 \%$; $\mathrm{TL}=6,30 \%$; and $\mathrm{CON}=3,15 \%$ attrition). At 3 months post, 25 families had withdrawn from the study $(\mathrm{AL}=10,48 \% ; \mathrm{TL}=9,45 \%$; and $\mathrm{CON}=6,30 \%)$. At 6 months post, attrition rates were $57 \%, 50 \%$, and $40 \%$ for $\mathrm{AL}, \mathrm{TL}$, and CON groups, respectively, similar to other health-related interventions involving adolescents. ${ }^{46}$

\section{Dose Delivered}

Overall, it took an average of $89 \pm 20$ minutes to complete the tour (Table 2). The TL tours were about 20 minutes shorter than the AL tours; by redesign, they took less time to complete than pre-test tours. ${ }^{30}$ 
Table 1. Sociodemographic Characteristics of Families That Participated in Grocery Store Tour Pilot Study

\begin{tabular}{|c|c|c|c|c|}
\hline Characteristics & All & Adult-Led & Teen-Led & Control Group \\
\hline $\begin{array}{l}\text { Parents }(\mathrm{n}=60) \\
\text { Age, y (mean }[ \pm \mathrm{SD}]) \\
\text { Race }(\% \text { white })^{\mathrm{a}} \\
\text { Ethnicity }(\% \text { not Hispanic) } \\
\text { Gender }(\% \text { female) } \\
\text { Marital status }(\% \text { married })^{\mathrm{c}} \\
\text { Education }(\% \text { bachelor's degree or higher })^{\mathrm{d}} \\
\text { Body mass index, } \mathrm{kg} / \mathrm{m}^{2},{\text { (mean }[ \pm \mathrm{SD}])^{\mathrm{e}}} \\
\text { Household income }(\% \geq \$ 70,001)^{f} \\
\text { Food security status }(\% \text { high })^{\mathrm{g}}\end{array}$ & $\begin{aligned} & 43( \pm 7) \\
& 77(n=46) \\
& 100(n=60) \\
& 92(n=55) \\
& 77(n=46) \\
& 85(n=51) \\
& 27( \pm 6) \\
& 52(n=31) \\
& 92(n=55)\end{aligned}$ & $\begin{array}{l}\text { Tour Parents }(n=20) \\
\qquad 4( \pm 5) \\
91(n=19) \\
100(n=20) \\
81(n=17) \\
72(n=15) \\
81(n=17) \\
27( \pm 6) \\
57(n=12) \\
95(n=20)\end{array}$ & $\begin{array}{l}\text { Tour Parents }(n=19) \\
\qquad \begin{array}{r}42( \pm 5) \\
80(n=16) \\
100(n=19) \\
95(n=19) \\
90(n=18) \\
85(n=17) \\
28( \pm 6) \\
60(n=12) \\
95(n=19)\end{array}\end{array}$ & $\begin{array}{l}\text { Parents }(\mathrm{n}=19) \\
43( \pm 9) \\
58(n=11) \\
100(n=19) \\
100(n=19) \\
69(n=13) \\
90(n=17) \\
26( \pm 5) \\
37(n=7) \\
84(n=16)\end{array}$ \\
\hline $\begin{array}{l}\text { Teens }(\mathrm{n}=70) \\
\text { Age, y (mean }[ \pm \mathrm{SD}]) \\
\text { Race }(\% \text { white) } \\
\text { Ethnicity }(\% \text { not Hispanic) } \\
\text { Gender (\% female) } \\
\text { Grade in school (mean }[ \pm \mathrm{SD}])\end{array}$ & $\begin{array}{l}12( \pm 1) \\
79(n=55) \\
96(n=67) \\
56(n=39) \\
7( \pm 1)\end{array}$ & $\begin{aligned} & \text { Tour Teens }(\mathrm{n}=26) \\
& 12( \pm 1) \\
& 81(\mathrm{n}=21) \\
& 100(\mathrm{n}=26) \\
& 62(\mathrm{n}=16) \\
& 6( \pm 1)\end{aligned}$ & $\begin{array}{l}\text { Tour Teens }(\mathrm{n}=23) \\
\qquad \begin{aligned} 12( \pm 1) \\
78(\mathrm{n}=18) \\
96(\mathrm{n}=22) \\
48(\mathrm{n}=11) \\
7( \pm 1)\end{aligned}\end{array}$ & $\begin{aligned} \text { Teens } & (\mathrm{n}=21) \\
12 & ( \pm 1) \\
76 & (\mathrm{n}=16) \\
91 & (\mathrm{n}=19) \\
57 & (\mathrm{n}=12) \\
6 & ( \pm 1)\end{aligned}$ \\
\hline $\begin{array}{l}\text { Food security status (\%) } \\
\text { High } \\
\text { Marginal } \\
\text { Low } \\
\text { Very low }\end{array}$ & $\begin{array}{c}67(n=46) \\
17(n=12) \\
15(n=10) \\
2(n=1)\end{array}$ & $\begin{array}{l}69(n=18) \\
19(n=5) \\
12(n=3) \\
0\end{array}$ & $\begin{array}{l}68(n=15) \\
14(n=3) \\
18(n=4) \\
0\end{array}$ & $\begin{aligned} 62(n=13) \\
19(n=4) \\
14(n=3) \\
5(n=1)\end{aligned}$ \\
\hline
\end{tabular}

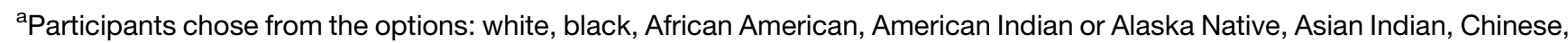
Filipino, Japanese, Korean, Vietnamese, Native Hawaiian, Guamanian or Chamorro, Samoan, or an other option for which spe-

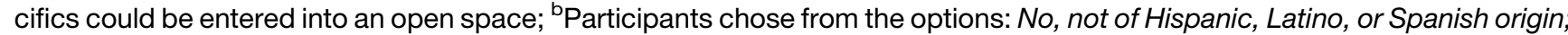
Yes, Mexican, Mexican American, Chicano; Yes, Puerto Rican; Yes, Cuban; or Yes, another Hispanic, Latino, or Spanish origin; ${ }^{\mathrm{C} P a r t i c i p a n t s ~ c h o s e ~ f r o m ~ t h e ~ o p t i o n s: ~ m a r r i e d, ~ l i v i n g ~ a s ~ m a r r i e d, ~ w i d o w e d, ~ o r ~ s i n g l e, ~ n e v e r ~ m a r r i e d ; ~}{ }^{\mathrm{d} P a r t i c i p a n t s}$ chose from the options: less than high school; high school diploma/general equivalency diploma; some college or post-high school but no degree or diploma; associate's (2-year) degree or vocational/technical diploma; bachelor's (4-year) degree; or graduate degree including master's, PhD, MD, DDS, etc; 'Participants reported height (in feet and inches) and weight in pounds; this was converted to kilograms and meters by an investigator who then calculated body mass index $\left(\mathrm{kg} / \mathrm{m}^{2}\right)$; ${ }^{\mathrm{f}} \mathrm{Participants}$ chose from the options: $<\$ 10,000, \$ 10,001$ to $\$ 30,000, \$ 30,001$ to $\$ 50,000, \$ 50,001$ to $\$ 70,000, \$ 70,001$ to $\$ 90,000$, or $>\$ 90,001$; ${ }^{9}$ Participants completed the Six-Item Short Form of the Food Security Survey Module and were categorized into food security categories of high, marginal, or low based on Bickel et $\mathrm{al} ;{ }^{35}$; hParticipants completed the Self-administered Food Security Survey Module for Children Ages 12 Years and Older and were categorized into food security categories of high, marginal, or low based on Connell et al. ${ }^{36}$

Note: Sixty-one families consented to participate in the study but 1 parent-child dyad was unable to remain at the information session where demographic information was collected owing to a family emergency and thus had missing data for all items.

\section{Fidelity}

Table 2 lists results from process observation checklists. Leaders in both groups were able to complete the majority of tasks well.

Process observation notes from the 15 tours reflected issues of (1) participant engagement; (2) speech, sound, and volume; (3) activity comments; (4) the ability to address participant comments; (5) difficulties using in-store examples; and (6) enhancements of presentation. The first 4 issues were observed in the $\mathrm{AL}$ and $\mathrm{TL}$ groups whereas the latter 2 were observed in only 1 of the 2 groups. Parents appeared more engaged than adolescents and participants became easily distracted near the end of tours. Teen leaders were perceived as talking too quickly or speaking too quietly, whereas ALs were thought to have good speaking volume and to cover information slowly. The main activity was perceived as instigating good conversations among participants and was enjoyed by attendees in the AL tours, but was not adequately explained or timed in TL tours. Adult leaders were thought to have answered questions well, whereas TLs were inconsistent (from answering questions well to having difficulty answering questions).
Teen leaders were perceived as having difficulties identifying in-store examples, forgetting to show examples of certain foods, using incorrect examples, or not finding appropriate examples. Adult leaders were observed using a hands-on approach, explaining concepts well, improvising for attendees, and providing a quality presentation.

In the tour perception questionnaire, the majority of participants (>75\%) reported enjoying the tour and understanding concepts and skills and would recommend the tour to other families. Suggestions for improvements included more practice comparing labels and knowledge for 
Table 2. Comparison of Process Observations of Grocery Store Tours $(n=15)$ for Parents and Their Adolescents When Taught by Adult or Teen Leaders

\begin{tabular}{|c|c|c|c|}
\hline Component of Checklist & $\begin{array}{l}\text { All Tours } \\
(n=15)\end{array}$ & $\begin{array}{l}\text { Adult-Led } \\
\text { Tours }(n=8)\end{array}$ & $\begin{array}{l}\text { Teen-Led } \\
\text { Tours }(n=7)\end{array}$ \\
\hline Attendance (\%; actual number of attendees divided by expected [ $\pm S D]$ ) & $83( \pm 28)$ & $100( \pm 24)$ & $64( \pm 20)$ \\
\hline Attendees, n ( $\pm S D)$ & $5( \pm 2)$ & $5( \pm 2)$ & $4( \pm 2)$ \\
\hline Workshop length, min $( \pm S D)$ & $89( \pm 20)$ & $100( \pm 19)$ & $77( \pm 13)$ \\
\hline \multicolumn{4}{|l|}{ Assessment of tasks (\% completed well) } \\
\hline Learning objectives clearly stated & $100(n=15)$ & $100(n=8)$ & $100(n=7)$ \\
\hline Clearly describes steps to reading nutrition facts labels & $100(n=15)$ & $100(n=8)$ & $100(n=7)$ \\
\hline Clearly describes steps to reading ingredient lists & $100(n=15)$ & $100(n=8)$ & $100(n=7)$ \\
\hline Delivered Choose This Not That example & $100(n=15)$ & $100(n=8)$ & $100(n=7)$ \\
\hline Label Scavenger Hunt activity & $100(n=15)$ & $100(\mathrm{n}=8)$ & $100(\mathrm{n}=7)$ \\
\hline $\begin{array}{l}\text { Clearly describes tips for making healthy choices and saving costs in } \\
\text { perimeter }\end{array}$ & $100(n=15)$ & $100(n=8)$ & $100(n=7)$ \\
\hline Identified in-store examples from Illinois ... What's in Season handout & $87(n=13)$ & $88(n=7)$ & $86(n=6)$ \\
\hline Identified in-store examples from Ripeness Test handout & $100(n=15)$ & $100(n=8)$ & $100(n=7)$ \\
\hline Delivered Food Cost Comparisons \#1 example & $100(n=15)$ & $100(n=8)$ & $100(n=7)$ \\
\hline $\begin{array}{l}\text { Clearly describes tips for making healthy choices and saving costs in } \\
\text { refrigerator aisle }\end{array}$ & $93(n=14)$ & $100(n=8)$ & $86(n=6)$ \\
\hline Identified in-store fat-free dairy examples & $93(n=14)$ & $100(n=8)$ & $86(n=6)$ \\
\hline Delivered Food Cost Comparisons \#2 example & $100(n=15)$ & $100(n=8)$ & $100(n=7)$ \\
\hline Clearly described tips for making healthy choices in pantry aisle & $100(n=15)$ & $100(n=8)$ & $100(n=7)$ \\
\hline $\begin{array}{l}\text { Identified in-store examples of cereal and bread with and without whole } \\
\text { grains }\end{array}$ & $80(n=12)$ & $88(n=7)$ & $71(n=5)$ \\
\hline $\begin{array}{l}\text { Clearly described tips for making healthy choices and saving costs in dry } \\
\text { food aisle }\end{array}$ & $93(n=14)$ & $100(n=8)$ & $86(n=6)$ \\
\hline $\begin{array}{l}\text { Identified in-store cost comparisons example of brand name vs generic } \\
\text { form of beans and legumes }\end{array}$ & $80(n=12)$ & $100(n=8)$ & $57(n=4)$ \\
\hline $\begin{array}{l}\text { Identified in-store examples of nuts with and without added sugar and } \\
\text { sodium }\end{array}$ & $87(n=13)$ & $100(n=8)$ & $71(n=5)$ \\
\hline $\begin{array}{l}\text { Clearly described tips for making healthy choices and saving costs in } \\
\text { freezer aisle }\end{array}$ & $100(n=15)$ & $100(n=8)$ & $100(n=7)$ \\
\hline $\begin{array}{l}\text { Identified in-store examples of fruits and vegetables with and without } \\
\text { added calories and sodium }\end{array}$ & $93(n=14)$ & $100(n=8)$ & $86(n=6)$ \\
\hline $\begin{array}{l}\text { Identified in-store examples of brand name vs generic forms of fruits and } \\
\text { vegetables }\end{array}$ & $93(n=14)$ & $100(n=8)$ & $86(n=6)$ \\
\hline Clearly summarized grocery shopping tips & $100(n=15)$ & $100(n=8)$ & $100(n=7)$ \\
\hline Completed well, of all 21 Tasks ( \pm SD) & $95 \pm 5$ & $99 \pm 2$ & $91 \pm 4$ \\
\hline
\end{tabular}

cooking or menu planning and less time standing. The majority of attendees (>85\%) liked the handouts and 100\% reported that they were helpful.

\section{Dose Received}

Parents had a baseline knowledge score of $8.17 \pm 1.40$ and there was no significant change from pre to post (Figure 2A). However, adolescents had a baseline knowledge score of $5.94 \pm 1.76$ that significantly increased $(P<.001)$ from pre to post $(7.25 \pm 1.47)$ (Figure $2 \mathrm{C})$ and in the AL $(P<.005)$, TL $(P<.005)$, and CON $(P<.05)$ groups (Figure $2 \mathrm{D})$.
The grocery shopping-related selfefficacy score of parents significantly increased $(P<.001)$ from pre $(3.87 \pm 0.62)$ to post $(4.37 \pm 0.51)$ (Figure 3A). Parents had significant increases in the self-efficacy score in the $\mathrm{AL}(P<.005)$, TL $(P<.005)$, and CON $(P<.001)$ groups (Figure $3 \mathrm{~B})$. When scores at post were compared among groups, parents in the $\mathrm{AL}$ $(4.59 \pm 0.33)$ and $\mathrm{TL}$ groups $(4.49 \pm 0.46)$ had significantly greater scores $(P<.05)$ than did those in the CON group (4.05 \pm 0.56). Overall, their grocery shopping-related self-efficacy score for adolescents also significantly increased $(P<.05)$ from pre $(3.31 \pm 0.79)$ to post $(3.75 \pm 0.71)$
(Figure 3C). When each group was evaluated, only the AL and TL groups had significant increases in scores $(P<.05)$ from pre to post (Figure 3D). However, there were no significant differences between adolescent selfefficacy scores between groups at post-tour $(P>.05)$.

\section{Program Impact}

Compared with pre-post, the overall parent knowledge score was significantly lower at 3 and 6 months post (Figure 2A). When examined by group, only the CON group parents demonstrated a decline (Figure 2B). 


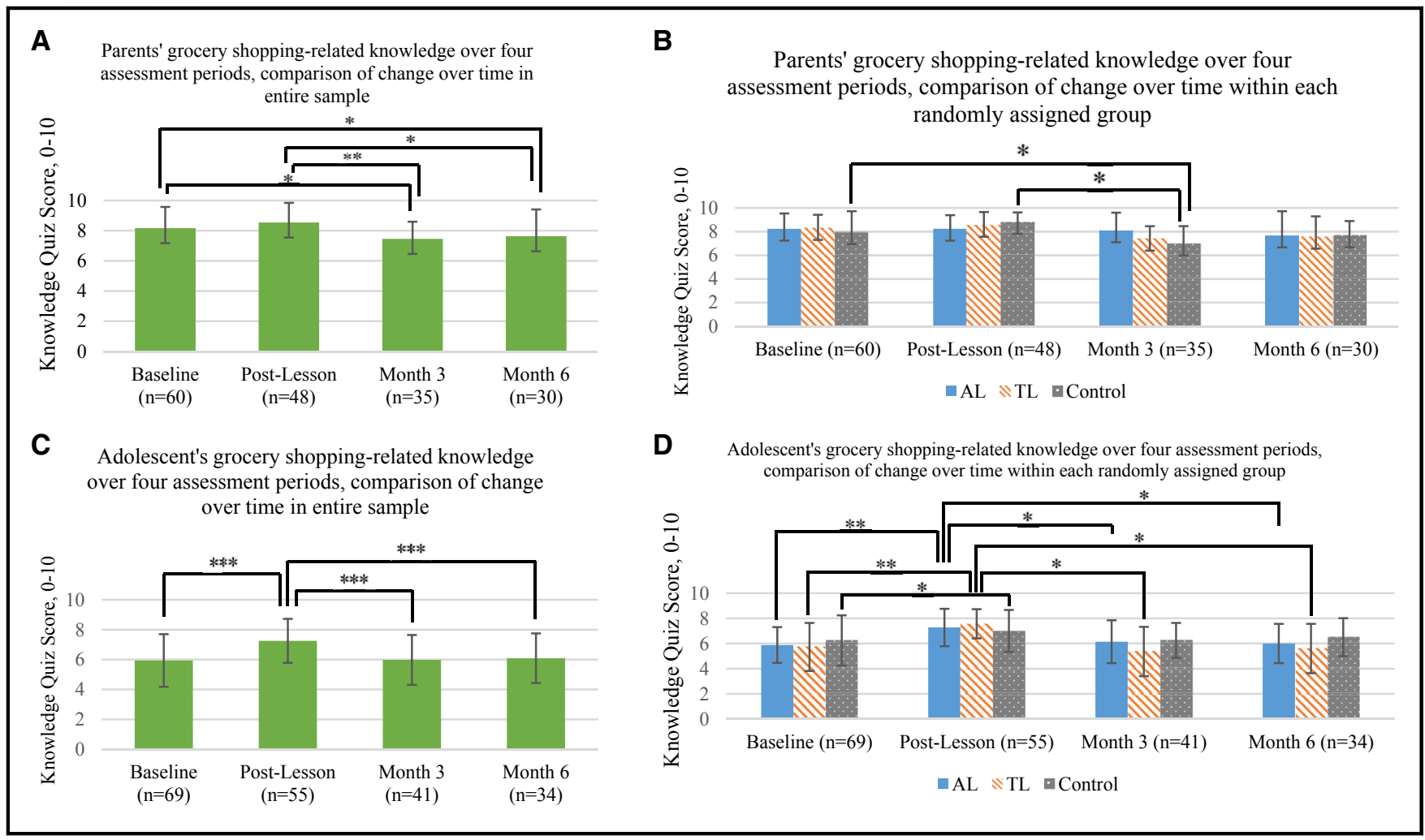

Figure 2. Grocery shopping-related knowledge of parents and adolescents in a 6-month randomized, controlled pilot study of a grocery store tour in which families were randomly assigned to an adult-led tour group (AL), a teen-led tour group (TL), or a control group. ${ }^{\star} P<.05$; ${ }^{\star \star} P<.005 ;{ }^{\star \star \star} P<.001$, based on Kruskal-Wallis tests. For parents: at baseline, $\mathrm{AL}(\mathrm{n}=21)$, TL $(\mathrm{n}=20)$, and control $(\mathrm{n}=20)$; at post, $\mathrm{AL}$ $(n=17), T L(n=14)$, and control $(n=17)$; at 3 months, $A L(n=11), T L(n=11)$, and control $(n=14) ;$ and at 6 months, $A L(n=9), T L(n=10)$, and control $(n=12)$. For adolescents: at baseline, $A L(n=26), T L(n=22)$, and control $(n=22)$; at post, $A L(n=22), T L(n=14)$, and control $(n=19)$; at 3 months, $\operatorname{AL}(n=14)$, TL $(n=11)$, and control $(n=16)$; and at 6 months, $\operatorname{AL}(n=10)$, TL $(n=10)$, and control $(n=14)$.

Adolescents had a significant decrease in knowledge score from post to 3 and 6 months post (Figure 2C). By group, adolescent knowledge scores declined in only the $\mathrm{AL}$ and TL groups from post to 3 and 6 months post (Figure 2D).

The parent self-efficacy score remained significantly greater at 3 and 6 months post compared with pre (Figure 3A) and in the $\mathrm{AL}$ and $\mathrm{TL}$ groups, but not the CON group (Figure 3B). In addition, the parent self-efficacy score in the AL group $(4.43 \pm 0.46)$ was significantly greater $(P<.05)$ than that of the CON group $(4.30 \pm 0.54)$. Adolescents retained an increase in the self-efficacy score from pre $(3.31 \pm 0.79)$ to 3 months post $(3.56 \pm 0.65)$ and 6 months post (3.62 \pm 0.62$)$ (Figure 3C). Only adolescents in the AL group had a significant increase from pre $(3.48 \pm 0.90)$ to 3 months post $(3.87 \pm 0.76)$ (Figure 3D).

On the strategy use questionnaire, all parents reported increasing an average of $6.5 \pm 4.19$ behaviors that were encouraged in the grocery store tour during the following 6 months. The number of behaviors parents reported increasing was not significantly different among groups $(P>.05)$.

\section{DISCUSSION}

The overall results indicate that the experience and outcomes from attending a grocery store tour were positive and beneficial for attendees. The current study supported the feasibility of grocery store tours being taught by TLs (ie, peers) to parents and their adolescents. Teen-led tours took less time to complete compared with AL tours. Despite a difference in duration, a majority of components were considered to have been completed well by a process observer in both tour types. Previous research demonstrated the feasibility of TLs in the school setting, ${ }^{47}$ and the current pilot study demonstrated their capa- bility in a grocery store setting. Qualitative process observation comments and participant perceptions suggested that TLs need further support to lead grocery store tours most effectively. In a previous study by Story and colleagues, $^{47}$ even when peer leaders were provided a full day of intensive training, $45 \%$ reported a desire for further training. Story and colleagues also reported that an adult teacher's presence at each lesson was important for the quality of the program's implementation. The current work confirmed that additional training before tours or adult support during tours may be needed for teens, although this may diminish the capacity for social modeling that TLs provide to peers. $^{12}$

Recruitment for grocery store tours with an audience of parents and their adolescents was similarly feasible. Electronic listservs and fliers were the most frequently reported recruiting avenues for this population. Lack of time was the most frequently reported 


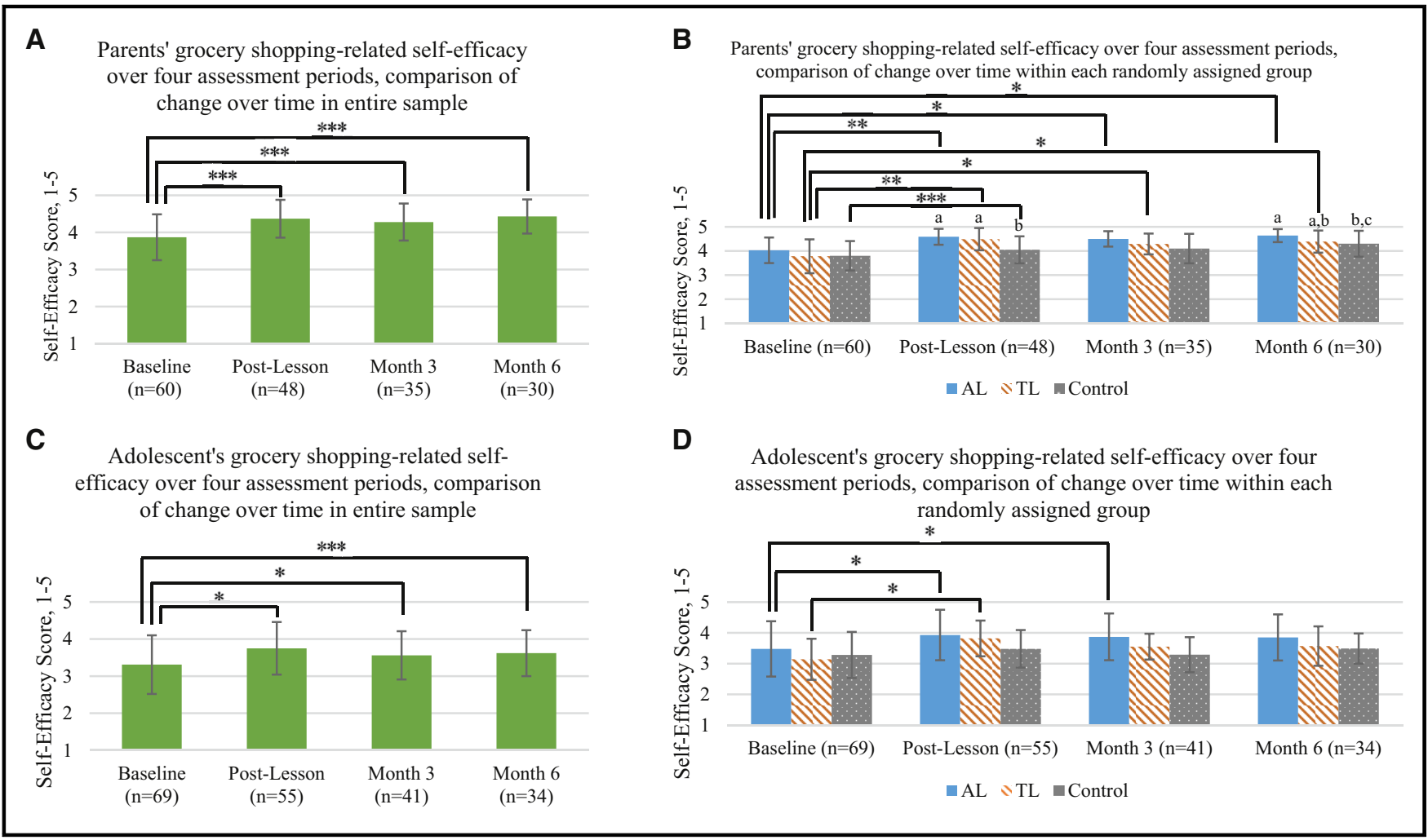

Figure 3. Average self-reported grocery shopping-related self-efficacy of parents and adolescents in a 6-month, randomized controlled pilot study of a grocery store tour in which families were randomly assigned to an adult-led tour group (AL), a teen-led tour group (TL), or a control group. ${ }^{\star} P<.05 ;{ }^{\star \star} P<.005 ;{ }^{\star \star \star} P<.001$, based on Kruskal-Wallis tests. ${ }^{\text {a-c }}$ Significant differences between groups at each time, based on Mann-Whitney $U$ test. For parents: at baseline, $A L(n=21), T L(n=20)$, and control $(n=20)$; at post, $A L(n=17), T L(n=14)$, and control $(n=17)$; at 3 months, $\operatorname{AL}(n=11), T L(n=11)$, and control $(n=14)$; and at 6 months, $\operatorname{AL}(n=9), T L(n=10)$, and control $(n=12)$. For adolescents: at baseline, $A L(n=26), T L(n=22)$, and control $(n=22)$; at post, $A L(n=22), T L(n=14)$, and control $(n=19)$; at 3 months, $\operatorname{AL}(n=14), T L(n=11)$, and control $(n=16)$; and at 6 months, $A L(n=10), T L(n=10)$, and control $(n=14)$.

reason for not participating; this likely stemmed from the work-life balance that many American families experience. ${ }^{48}$ Future tours could be developed to capitalize on the time spent in stores as part of routine grocery store shopping trips, which amounts to an average of $42 \mathrm{~min} / \mathrm{wk}^{2}$ Among those who could participate in the tour, many reported desiring more practice with the information provided, development of complementary skills (such as menu planning and cooking), and access to reputable online resources that could be used after the tour. This supports the notion that healthy eating behaviors require several interconnected skill sets, which could be supported through a set of courses instead of a standalone tour or lesson, and by providing online supplementary materials. In addition, SCT supports the use of additional practice or mastery experiences, particularly in more difficult and challenging circumstances, that influence an individual's self-efficacy more strongly to perform healthful grocery shopping behaviors. ${ }^{12}$

Conducting nutrition education using grocery store tours presents unique considerations for program administrators. Some participants mentioned that they did not enjoy the amount of standing and walking required for the tour. The ability to stand for long periods of time may be a barrier to participation unless grocery store tours integrate sitting breaks or motorized chairs are provided for attendee use. Grocery stores also have limited space, which reduces the number of attendees who can be included on each tour (about 4-5 participants/tour in the current study). This may require more sessions to be provided with a few number of attendees, compared with traditional venues that can accommodate larger numbers in fewer sessions. Alternative education methods that require less facilitator time commit- ments could be explored, such as educational podcasts for use while grocery shopping. ${ }^{49}$

Results for grocery shoppingrelated knowledge among parents and adolescents in this study did not support the related hypothesis. Only adolescents had significant increases in knowledge from baseline to posttour, and this was true for even those who received no intervention. In addition, parents and adolescents in the current study displayed a high level of knowledge at baseline that left little room for improvement. Quiz-style questionnaires were used in the past to assess adult and child knowledge acquired during grocery store tours. ${ }^{11,12,37,38}$ However, nutrition knowledge was not correlated with dietary behavior when it was assessed among adolescents ${ }^{50}$ and the relationship in adults was modest. ${ }^{51}$ At 3- and 6-month post- intervals, participants in the current study experienced significant decreases in quiz scores 
compared with post-tour, indicating poor knowledge retention. Thus, the current findings seemed to converge with the growing consensus in the field of behavioral nutrition that increasing knowledge alone is not sufficient for behavior change.

Results from the self-efficacy and lesson strategy questionnaires completed by parents and adolescents provided more promising indications that participants may be positively affected by their tour attendance up to 6 months afterward. Self-efficacy is a critical component of the SCT, ${ }^{12}$ and Rimal $^{52}$ showed that self-efficacy mediates the relationship between behavior and knowledge. In the current pilot study, both parents and adolescents had positive changes in selfefficacy scores at all 3 post-intervals compared with baseline. Either these improvements were only in the AL and TL groups or the post-tour scores were significantly lower in CON attendees. Carson and $\mathrm{Hedl}^{37}$ published the only grocery store tour study that assessed selfefficacy among participants; they found improvements among participants who attended both a single tour and 3 of them. The current findings were similarly positive but were based on a 15item questionnaire compared with a single-item that was used previously. When adolescent groups were compared individually, only those in the AL group had significant increases at 3 months post but not 6 months post. These less consistent self-efficacy results among adolescents, compared with their parents, may have resulted from their low level of involvement with the regular grocery shopping routine. This may preclude opportunities to practice skills (ie, mastery experiences), 1 of the 4 critical methods illustrated in the SCT for self-efficacy to be developed. ${ }^{12}$ Parents reported that on average, they increased their use of approximately 6 strategies that were taught in the tour over the 6 months that followed the intervention. Nevertheless, future studies should employ an objective measure of behavior change, such as sales receipts.

The current study had several limiting factors that should be considered. Recruitment did not yield the desired sample size, and a higher proportion of participating parents were female with higher incomes and education levels than the population in surrounding residential areas. These limitations, compiled with a high attrition rate over the 6-month data collection, reduced the statistical power as well as the generalizability of the results. It is possible that the sample may have been biased toward those with high interest and engagement levels among tour attendees and unmeasured motivation to return materials among those who completed follow-up assessments. Nonetheless, significant self-efficacy and perceived behavior outcomes suggest that the tour had a positive impact on participants. Social desirability bias may be a potential explanation for self-efficacy results, although this is inherent in all self-report measures. Finally, it was not possible to pilot test survey instruments before data collection began, but the self-efficacy scale displayed high internal reliability.

\section{IMPLICATIONS FOR RESEARCH AND PRACTICE}

It is feasible to provide grocery store tours to parents and their adolescents. Recruitment using electronic listservs and fliers generates numerous inquiries but time constraints may prevent parents from participating. Teen leaders were able to conduct grocery store tours to a degree of adequacy similar to that of ALs. However, additional support such as extra leadership training may be necessary to maximize TLs' effectiveness. Positive effects from the tour, even when assessed 6 months later, were noted for both parents and adolescents despite a largely absent change in knowledge. Future research should investigate whether grocery store tours affect behavior change, using objective measures.

\section{ACKNOWLEDGMENTS}

The authors thank the local County Market store directors for allowing the research team to conduct this grocery store tour within their stores.

\section{REFERENCES}

1. Bureau of Labor Statistics. Consumer expenditures - 2014. http://www.bls. gov/news.release/pdf/cesan.pdf. Accessed June 9, 2016.
2. Bureau of Labor Statistics. Time spent in detailed primary activities and percent of the civilian population engaging in each activity, averages per day by sex, 2015 annual averages. http://www.bls.gov/tus/tables/a1_2015. pdf. Accessed December 5, 2016.

3. US Department of Health and Human Services and US Department of Agriculture. Dietary Guidelines for Americans 2015-2020. https://health.gov/ dietaryguidelines/2015/resources/20152020_Dietary_Guidelines.pdf. Accessed November 14, 2016.

4. Kelder SH, Perry CL, Klepp KI, Lytle LL. Longitudinal tracking of adolescent smoking, physical activity, and food choice behaviors. Am J Public Health. 1994;84:1121-1126.

5. Post GB, de Vente W, Kemper HC, Twisk JW. Longitudinal trends in and tracking of energy and nutrient intake over 20 years in a Dutch cohort of men and women between 13 and 33 years of age: the Amsterdam growth and health longitudinal study. $\mathrm{Br} J$ Nutr. 2001;85:375-385.

6. Campos S, Doxey J, Hammond D. Nutrition labels on pre-packaged foods: a systematic review. Public Health Nutr. 2011;14:1496-1506.

7. Lewis KH, Roblin DW, Leo M, Block JP. The personal shopper-a pilot randomized trial of grocery storebased dietary advice. Clin Obes. 2015; 5:154-161.

8. Nikolaus CJ, Muzaffar H, NickolsRichardson SM. Grocery store (or supermarket) tours as an effective nutrition education medium: a systematic review. J Nutr Educ Behav. 2016;48:544-554.

9. Sadler MJ, Fine G, Richards S, Read L. Healthy Heart Store Tours - a useful communication tool? Nutr Bull. 2003; 28:179-186.

10. Baic S, Thompson JL. Prevent it: using grocery store tours as an educational tool to promote heart health. ACSM Health Fitness J. 2007;11:15-20.

11. Lafferty A, Marquart L, Reicks M. Hunting for whole grains: a supermarket tour. J Nutr Educ Behav. 2006;38: 197-198.

12. McAlister A, Perry C, Parcel GS. How individuals, environments, and health behaviors interact. In: Glanz K, Rimer BK, Viswanath K, eds. Health Behavior and Health Education: Theory, Research, and Practice. 4th ed. San Francisco, CA: JosseyBass; 2008:169-188. 
13. Stok FM, de Vet E, de Wit JBF, Luszczynska A, Safron M, de Ridder DTD. The proof is in the eating: subjective peer norms are associated with adolescents' eating behavior. Public Health Nutr. 2015;18:1044-1051.

14. Ayaz S, Acil D. Comparison of peer education and the classic training method for school aged children regarding smoking and its dangers. I Pediatr Nurs. 2015;30:e3-e12.

15. Maticka-Tyndale E, Barnett JP. Peerled interventions to reduce HIV risk of youth: a review. Eval Program Plann. 2010;33:98-112.

16. Faggiano F, Vigna-Taglianti F, Burkhart $G$, et al. The effectiveness of a school-based substance abuse prevention program: 18-month follow-up of the EU-Dap cluster randomized controlled trial. Drug Alcohol Depend. 2010;108:56-64.

17. Nelson SA, Nickols-Richardson SM. A systematic review of peer nutrition education in childhood and adolescence. Health Behav Policy Rev. 2014;1: 247-264.

18. Guidetti M, Conner M, Prestwich A, Cavazza N. The transmission of attitudes towards food: twofold specificity of similarities with parents and friends. Br J Health Psychol. 2012;17:346-361.

19. Peneau S, Mekhmoukh A, Chapelot D, et al. Influence of environmental factors on food intake and choice of beverage during meals in teenagers: a laboratory study. Br J Nutr. 2009;102:1854-1859.

20. Salvy S-J, Coelho JS, Kieffer E, Epstein LH. Effects of social contexts on overweight and normal-weight children's food intake. Physiol Behav. 2007;92:840-846.

21. Salvy S-J, Howard M, Read M, Mele E. The presence of friends increases food intake in youth. Am J Clin Nutr. 2009;90:282-287.

22. Salvy S-J, Romero N, Paluch R, Epstein LH. Peer influence on preadolescent girls' snack intake: effects of weight status. Appetite. 2007;49: 177-182.

23. Kahn RF, O'Sullivan P, Vannatta PM. Supermarket tour: the effect of presentation mode on nutrition knowledge and attitudes. Fam Med. 2003;35: 721-725.

24. Silzer JS, Sheeshka J, Tomasik HH, Woolcott DM. An evaluation of Supermarket Safari nutrition education tours. J Can Diet Assoc. 1994;55:179-183.

25. Scott JA, Pollard CM. Supermarket sleuth: evaluation of a novel nutrition education strategy. Aust J Nutr Diet. 1992;49:11-17.

26. Clemson Cooperative Extension. Food shopping. http://www.clemson.edu/ extension/hgic/food/nutrition/food_shop_ prep/food_shop. Accessed August 17, 2017.

27. Iowa State University Extension and Outreach. Spend smart. Eat smart. http://www.extension.iastate.edu/food savings. Accessed June 3, 2013.

28. University of Minnesota Extension. Stretching your food dollar. http://www. extension.umn.edu/family/live-healthy-livewell/healthy-minds/getting-through-toughtimes/stretching-your-food-dollar/. Accessed August 17, 2017.

29. University of Missouri Extension. Squeezed by rising food prices? http:// extension.missouri.edu/p/MP905. Accessed June 3, 2013.

30. Graziose M. Development and process evaluation of an in-store grocery shopping lesson for adolescents and their parents (master's thesis). https://etda. libraries.psu.edu/catalog/18708. Accessed May 28, 2016.

31. Miller CK, Gutschall MD, Lawrence F. The development of self-efficacy and outcome expectation measures regarding glycemic load and the nutrition management of type 2 diabetes. Public Health Nutr. 2007;10:628-634.

32. Townsend MS, Johns M, Shilts MK, Farfan-Ramirez L. Evaluation of a USDA nutrition education program for low-income youth. J Nutr Educ Behav. 2006;38:30-41.

33. Steckler A, Linnan L. Process Evaluation for Public Health Interventions and Research. San Francisco, CA: Jossey-Bass; 2002.

34. US Census Bureau. State and County Quickfacts: Urbana City and Champaign City, Illinois. http://quickfacts. census.gov. Accessed June 17, 2017.

35. Bickel G, Nord M, Price C, Hamilton W, Cook J. Guide to Measuring Household Food Security. Alexandria, VA: US Dept of Agriculture, Food and Nutrition Service; 2000:1-82.

36. Connell CL, Nord M, Lofton KL, Yadrick K. Food security of older children can be assessed using a standardized survey instrument. J Nutr. 2004;134:2566-2572.

37. Carson JAS, Hedl JJ. Smart Shoppers Tour: outcome evaluation. J Nutr Educ. 1998;30:323-331.

38. van Assema P, Cremers S, Van Dis I. Nutrition education tours in the supermarket: the results of a pilot project in the Netherlands. Food Choice Conference, Adelaide; 1996:174-178.
39. Fitzgerald A, Heary C, Kelly C, Nixon E, Shevlin M. Self-efficacy for healthy eating and peer support for unhealthy eating are associated with adolescents' food intake patterns. Appetite. 2013;63:48-58.

40. Carson JAS, Gillham MB, Kirk LM, Reddy ST, Battles JB. Enhancing selfefficacy and patient care with cardiovascular nutrition education. Am J Prev Med. 2002;23:296-302.

41. Faul F, Erdfelder E, Lang AG, Buchner A. G*Power 3: a flexible statistical power analysis program for the social, behavioral, and biomedical sciences. Behav Res Methods. 2007;39: 175-191.

42. Paineau DL, Beaufils F, Boulier A, et al. Family dietary coaching to improve nutritional intakes and body weight control: a randomized controlled trial. Arch Pediatr Adolesc Med. 2008;162: 34-43.

43. Curtis PJ, Adamson AJ, Mathers JC. Effects on nutrient intake of a family-based intervention to promote increased consumption of low-fat starchy foods through education, cooking skills and personalised goal setting: the Family Food and Health Project. $\mathrm{Br} J$ Nutr. 2012;107: 1833-1844.

44. Fagerland MW. t-tests, non-parametric tests, and large studies - a paradox of statistical practice? BMC Med Res Methodol. 2012;12:78.

45. Robson SM, Stough CO, Stark LJ. The impact of a pilot cooking intervention for parent-child dyads on the consumption of foods prepared away from home. Appetite. 2016;99: 177-184.

46. Evans RK, Franco RL, Stern M, et al. Evaluation of a 6-month multidisciplinary healthy weight management program targeting urban, overweight adolescents: effects on physical fitness, physical activity, and blood lipid profiles. Int J Pediatr Obes. 2009;4: 130-133.

47. Story M, Lytle LA, Birnbaum AS, Perry CL. Peer-led, school-based nutrition education for young adolescents: feasibility and process evaluation of the TEENS study. J Sch Health. 2002; 72:121-127.

48. Presser HB. Working in a 24/7 Economy: Challenges for American Families. New York, NY: Russell Sage Foundation; 2005.

49. Bangia D, Palmer-Keenan DM. Grocery store podcast about omega-3 fatty 
acids influences shopping behaviors: a pilot study. J Nutr Educ Behav. 2014; 46:616-620.

50. Pirouznia M. The association between nutrition knowledge and eating behavior in male and female adolescents in the US. Int J Food Sci Nutr. 2001;52: 127-132.

51. Tepper BJ, Choi YS, Nayga RM. Understanding food choice in adult men: influence of nutrition knowledge, food beliefs and dietary re- straint. Food Qual Prefer. 1997;8: 307-317.

52. Rimal RN. Closing the knowledgebehavior gap in health promotion: the mediating role of self-efficacy. Health Commun. 2000;12:219-237.

\section{Thinking About Writing a Letter to the Editor?}

Letters to the Editor are timely and succinct expressions of responsible criticism or reaction to material published in recent issues. Submission of a Letter to the Editor constitutes permission for JNEB to publish it with or without editing and abridgment. Authors of the articles referred to in Letters to the Editor will be given an opportunity to respond in a letter for simultaneous publication. 


\section{CONFLICT OF INTEREST}

The C.J.N. was supported by a Kraft Human Nutrition Fellowship through the Division of Nutritional Sciences at the University of Illinois at the time that this work was conducted. The S.M.N.-R. has received research support from the US Department of Agriculture, National Institute of Food and Agriculture (Award No. 2012-68001-22032); the Bell Institute of Nutrition and Health, General Mills, Inc; the Dairy Management Institute; and the McCormick Science Insti- tute within the past 3 years. Any opinions, findings, conclusions, or recommendations expressed in this publication are those of the author(s) and do not necessarily reflect the view of the US Department of Agriculture. M.M.G. has not stated any conflicts of interest. 